\title{
Disaster risk reduction activities as learning
}

\author{
Kaori Kitagawa ${ }^{1}$ D
}

Received: 18 May 2020 / Accepted: 19 November 2020 / Published online: 4 December 2020

(c) The Author(s) 2020

\begin{abstract}
The purpose of this paper is to relate disaster risk reduction activities to learning perspectives and theories. The paper refers to 'disaster risk reduction activities' encompassing various terms used in the existing disaster risk management literature, such as 'disaster education' and 'capacity building'. One thing they have in common is the involvement of the general public in preparing for natural hazards. Disaster risk reduction activities involve learning, because they aim to change people's behaviour, perception and emotion. An overview of the relationships between disaster risk reduction activities and learning theories has not been offered, and that is what this paper aims to achieve. 'How people learn' has been studied in the fields of psychology and education over the years. Evolving from the primary focus of acquisition of knowledge and skills, the understanding of 'what learning is' has broadened to envisage emotional and social dimensions. Referring to the historical development of five major learning perspectives, the paper links each perspective with specific disaster risk reduction activities. The foci of the studies of disaster risk reduction activities have been what people should learn, rather than how people learn. Engagement with learning perspectives and theories will allow conceptualising how people learn to be prepared and resilient, which will benefit disaster risk management.
\end{abstract}

Keywords Disaster risk management $\cdot$ Disaster risk reduction activities $\cdot$ Learning perspectives $\cdot$ Learning theories

\section{Introduction}

The purpose of this paper is to relate disaster risk reduction (DRR) activities to learning theories. The paper uses 'DRR activities' to encompass various terms used in the existing disaster risk management literature and research, such as 'disaster education', 'preparedness actions', 'capacity building' and 'awareness raising'. One thing they have in common is the involvement of the general public in preparing for natural hazards, whether in formal settings, e.g. at school or informal environments, e.g. in a household. The emphasis on

Kaori Kitagawa

k.kitagawa@ucl.ac.uk

1 Department of Education, Practice and Society, Institute of Education, University College London, 20 Bedford Way, London WC1H 0AL, UK 
DRR activities derives from the recognition that combining non-structural soft measures with structural hard measures is necessary for effective DRR (UNISDR 2015).

DRR activities involve learning, because they aim to change people's behaviour, perception and emotion (e.g. Preston 2012; Kitagawa 2017, 2019a; Kitagawa et al. 2017). Given the Sendai Framework for DRR 2015-2030 places 'education as a crosscutting issue' (Shiwaku et al. 2016, p. 261), it makes sense to discuss DRR activities from learning perspectives. However, an overview of the relationships between DRR activities and learning theories has not been offered, and that is what this paper aims to achieve. Gaining an overall understanding of how people learn and how it relates to DRR will contribute to informed decision-making in responding to the DRR needs of individuals and communities. Within the overview, the paper also aims to shed light on the applications of learning theories in DRR research. Some studies refer to specific learning theories in implementing DRR strategies (e.g. Johansson et al. 2013; Samaddar et al. 2015; McEwen et al. 2018). The paper examines the benefits and drawbacks in existing approaches.

'How people learn' has been studied in the fields of psychology and education over the years. Simultaneously, evolving from the primary focus of acquisition of knowledge and skills, the understanding of 'what learning is' has broadened to envisage emotional and social dimensions (Illeris 2009). There is also a consensus in educational research that people learn throughout their lives-lifelong - as well as in diverse settings-lifewide (Okumoto 2010; Jackson 2011). The development of learning theories corresponds to the development of ontological and epistemological perspectives on behaviour, mind and emotion. Within those perspectives, there are a number of sub-theories, theories of instruction/ instructional designs and methods of teaching, which are constantly being advanced (Weibell 2011). Some retain traditional interpretations of the perspectives, while others aim for novel approaches in understanding learning (Illeris 2009). This paper looks at the historical development of five major learning perspectives, using learning 'perspectives' to refer to major schools of thoughts (e.g. behaviourism, cognitivism) and learning 'theories' to refer to sub-theories within the perspectives (e.g. conditioning, scaffolding).

The literature used in the study was selected based on its credibility and relevance in connecting DRR activities and learning perspectives and theories. This study, therefore, is not a systematic literature review of either topic. For the literature on DRR activities, the research papers that studied DRR activities and published in international peer-reviewed journals were interrogated. The journals' fields included natural hazards (e.g. Natural Hazards), disaster risk management (e.g. International Journal of Disaster Risk Reduction, Disaster Prevention and Management), environmental studies (e.g. Environmental Science \& Policy, Ecology and Society, Journal of Environmental Planning and Management), psychology (e.g. The Journal of General Psychology, Annual Review of Psychology) and education (e.g. Pedagogy, Society and Culture, Compare). Some of these papers apply learning perspectives or theories, which are discussed in the subsequent sections.

For the literature on learning perspectives and theories, textbook-type of literature from educational psychology, learning theories, as well as original writings from theorists were reviewed to construct a summary of the historical development and the principles of learning perspectives and theories. Some journal papers which apply learning perspectives and theories in the practice in the fields of, for example, nursing and clinical medicine are also used as points of reference. There is a broad consensus that major learning perspectives are: behaviourism, cognitivism, constructivism (cognitive and social), humanism and connectivism. This paper focuses on the first three, and besides, 'social cognitivism theory' which entails the features of both behaviourism and cognitivism. Summarising these positions is an ambitious exercise, given behaviourism alone has 'at least' 15 variations (O'Donohue 
and Kitchener 1999). The strategy taken is to combine three to four representative pieces of literature to extract the perspective's position on what knowledge is, how people learn, the role of the instructor and the learner, methodologies for teaching and learning to describe the development and the principles of the perspective. Within each perspective, many learning theories have been developed, which include instructional designs and learning aids. The paper focuses on a few of the major theories which have relevance in discussing DRR activities. For behaviourism, cognitivism, cognitive constructivism, no DRR literature could be identified that discuss the DRR activities from those perspectives. Hence, this paper attempted to make a connection by applying a learning perspective to the activity.

\section{Rationale for including learning perspectives in DRR}

A rich body of literature and research are available, which develop, implement and evaluate DRR activities (e.g. Shaw et al. 2011; Johnson et al. 2014). The majority, however, focuses on the curricula, instructional methods or programme designs of DRR activities, rather than the learning process of those who are engaged in the activities. For example, Shaw, Shiwaku and Takeuchi's (2011) Disaster Education, one of the first comprehensive books on the topic, is a collection of DRR approaches and methods in various settings but does not necessarily engage in the issues around learning. This paper consolidates the growing argument that learning perspectives contribute to developing effective DRR activities (e.g. Reed et al. 2010; Preston 2012; Kitagawa 2017).

There are probably two groups of research that link DRR activities to learning. The first 'social learning' group is originated in the field of environmental management (e.g. Pahl-Wostl 2006; Muro and Jeffrey 2008; Cundill and Rodela 2012; Henly-Shepard et al. 2015; Benson et al. 2016; Fisher and Dodman 2019). Borrowing from them, DRR studies that refer to social learning are increasing, particularly concerning community-based DRR and participatory approaches (e.g. Johansson et al. 2013; Samaddar et al. 2015; Dittrich et al. 2016; Murti et al. 2020). The challenge of discussing social learning is its 'lack of conceptual clarity' (Reed et al. 2010) due to its multiple interpretations 'characterised by interdisciplinary endeavours and a range of borrowing practices' (Rodela 2013, p. 164). Acknowledging Bandura (1977) as the founder of 'social learning theory', studies diversely interpret and apply the concept. There is not yet an agreed position on what knowledge is, how people learn, the role of the instructor and the learner, methodologies for teaching and learning. For this developmental nature of the concept, this paper does not treat 'social learning' as a theory. The aim here is to discuss such diversities in the application of the concept, drawing on Reed et al.'s (2010) critical review of resource management literature.

Reed et al. (2010) address three confusions in the use of 'social learning'. The first is that the concept is often used as a synonym for 'participation' or 'collaboration'. Such 'supposed social learning projects' focus on stakeholder participation without discussing whether social learning occurred. The second confusion is 'mistaking social learning for its potential outcomes', such as pro-environmental behaviour. Social learning does not guarantee such an outcome; pro-environmental behaviour may develop without social learning. Third, social learning deals with both individual and wider social learning, which are separate but related learnings - this recognition is limited. The existing DRR literature that refers to social learning, although its number is small, shares such ambiguities. The trend seems to be the concept is used as an umbrella term to express their methodological stance-similar to the first point above-(e.g. Johansson et al. 2013; Murti and Mathez-Stiefel 2019) or their overall 
principle or goal—similar to the second point above-(e.g. Samaddar et al. 2015). The difference between individual and group learnings is acknowledged but not necessarily dealt with. In inquiring DRR activities as learning, the application of the concept of social learning should address 'learning'. Reed et al. (2010) propose one framework in achieving it: studies of social learning should demonstrate that: (1) 'a change in understanding has taken place in the individuals involved', (2) 'this change goes beyond the individual and becomes situated within wider social units or communities of practice' and (3) learning occurs 'through social interactions and processes between actors within a social network'.

The other group of social psychologists and information scientists deploy social constructivist learning perspectives in their pursuance of 'DRR human science (bosai ningen kagaku)' as a sub-field in DRR (Yamori and Miyamoto 2016). As opposed to conventional models which represent knowledge transmission from experts to non-experts, they propose a new framework for DRR activities that allows reciprocal interactions and collaborations between the two parties. Removing the expert/non-expert barrier contributes to raising non-experts' motivation to participate and a sense of ownership (Yamori 2011, 2020; Yamori and Miyamoto 2016; Kitagawa 2019b). The group has a clear epistemological stance of 'collaborative practice (kyodoteki jissen)' in forming 'communities of practice' (Lave and Wenger 1991). Their approach will be discussed further in a later section.

In summary, there is an increase in the number of DRR research that refers to learning. It is however fair to conclude that the application of learning perspectives and theories in DRR research is limited.

It is worth paying attention to another set of literature, which draws on cognitive and emotional psychology models intending to develop preparedness and resilience in people, even though its reference to learning is minimal. Spread across various fields of study including risk management, environmental studies and climate change adaptation, this group of research applies and furthers the models such as the protective motivation theory (e.g. Neuwirth et al. 2000; e.g. McCaughey et al. 2017), the theory of reasoned actions (e.g. Nguyen et al. 2018) the protective action decision model (e.g. Lindell and Perry 2012) or the community engagement theory (e.g. Paton 2008; Paton and Jang 2012). Broadly, these models allow an investigation and explanation of 'a development process that commences with factors that motivate people to prepare, progresses through the formation of intentions and culminates in decisions to prepare' (Paton 2003, p. 210). Most models accommodate psychological, socio-cultural, organisational and political 'factors' based on that scientific information on hazards and risks alone does not necessarily drive people to prepare for a disaster (Paton 2008).

Learning perspectives also help us to investigate and explain 'a development process' which entails motivation, intention, decision and action. The scope, however, is broader given learning perspectives and theories are ontologically and epistemologically framed, as this paper describes how each perspective defines what knowledge is, how people learn, the role of the instructor and the learner and methodologies for teaching and learning. In this light, learning perspectives and the existing psychology models are supplementary to each other and could be combined in considering and planning DRR activities. 


\section{Applying learning perspectives and theories in discussing DRR}

In this section, the paper links four major learning perspectives with DRR activities. After summarising each perspective and some of its theories, the section discusses both confirmed and speculative links between the perspective and theories and specific DRR activities. Table 1 is the overall summary of the discussion.

\subsection{Behaviourism}

Behaviourism developed between the end of the nineteenth century and the first half of the twentieth century. It considers knowledge exists outside of the person, and the primary concern is observable behaviour. Knowledge is acquired through modifying behaviour, and behaviour is determined by the environment (Eggen and Kauchak 1999; Schultz 2013). Learning is a change in observable behaviour and can be conditioned using positive or negative reinforcement. Behaviour resulting in positive reinforcement (reward) is a condition for good performance, while a behaviour resulting in negative reinforcement (punishment) is a condition for bad performance. Bad experiences can lead to fear or anxiety. Motivation to learn derives from factors in the environment, rather than from the person. This means motivation can be managed through the use of reward and punishment (Quinn 2000; Santrock 2018).

The predecessor of behaviourism was the Russian physiologist Pavlov, who studied stimulus-response relationships through laboratory experiments. His theory 'classical conditioning' refers to the process through which an association is made between a conditioned stimulus and an unconditioned response. Undertaking 'trial and error' experiments, Thorndike was the first psychologist, who introduced the idea of a 'law of effect' in explaining learning. A behaviour prompted by a stimulus achieving a wanted result will be a learned behaviour. When there is the same stimulus, the same response follows (Schunk 2012; Lefrançois 2019). With his book Behaviorism published in 1925, Watson is regarded as the founder of behaviourism. His goal was the prediction and control of behaviour. Skinner continued this line of work proposing 'operant conditioning'. Introducing 'reinforcement' to replace a 'law of effect', he argued a behaviour which is reinforced is likely to be strengthened, while a behaviour which is not reinforced is likely to be weakened. Thus, the shift from classical conditioning was on the view that learning depends on the consequences of behaviours (Sternberg and Williams 2010; Bohlin et al. 2012; Schultz 2013).

In behaviourism, the relationship between the instructor and the learner is instructorled, which means the instructor sets goals and objectives and demonstrates the level of performance for the learner to follow. The instructor transfers information to the learner, managing the learning environment and providing reinforcement. The learner is, therefore, a passive recipient of information and knowledge. (Schultz 2013; Kay and Kibble 2016). Methodologies focus on direct instruction and practice and repetition in learning. The instruction involves defining outcomes and explaining performing procedures. Evaluation is outcome-based with clear criterion reference. The role of the environment is vital, which should be stimulating and enhancing (Schunk 2012; Kay and Kibble 2016). 


\begin{tabular}{|c|c|c|c|c|c|}
\hline & 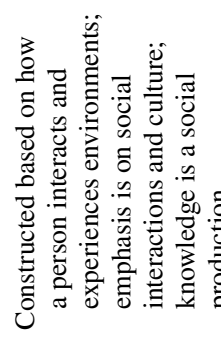 & 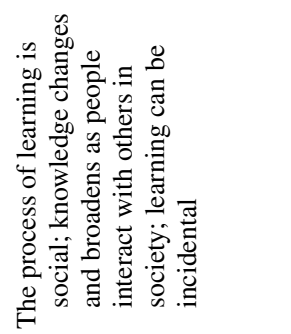 & 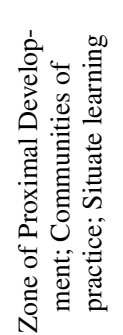 & 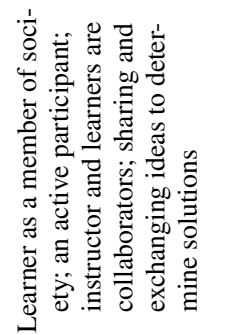 & 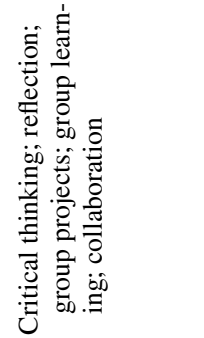 \\
\hline & 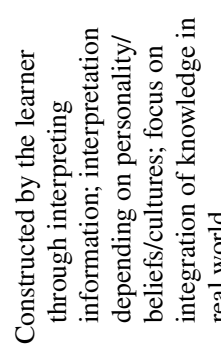 & 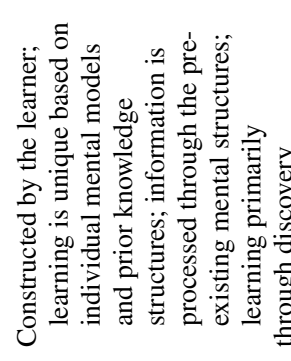 & 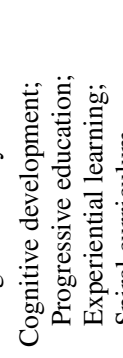 & 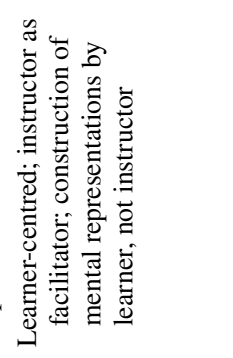 & 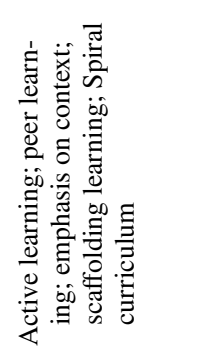 \\
\hline & 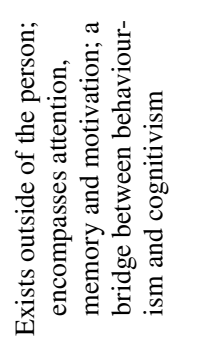 & 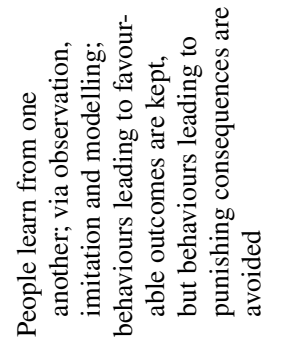 & 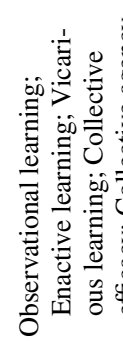 & 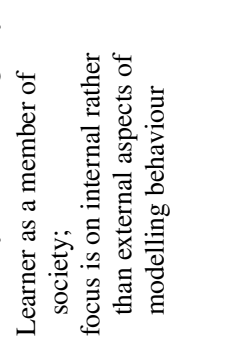 & 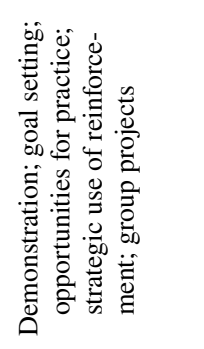 \\
\hline & 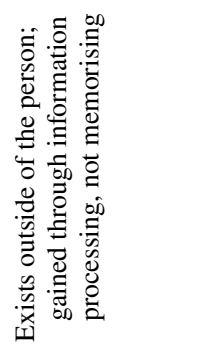 & 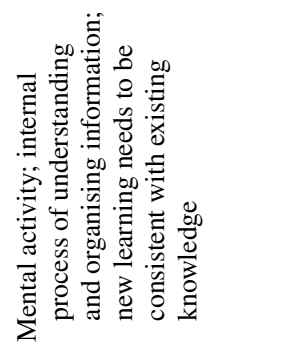 & 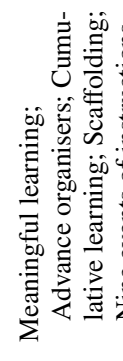 & 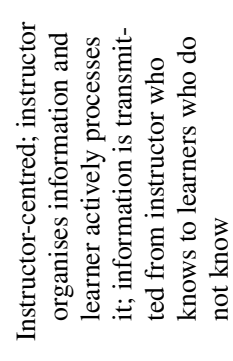 & 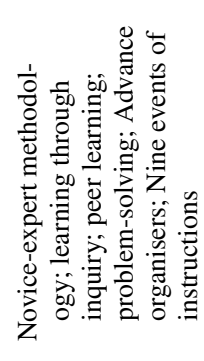 \\
\hline & 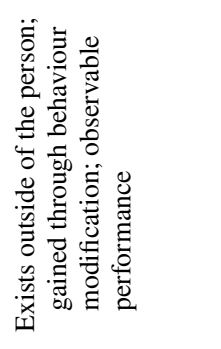 & 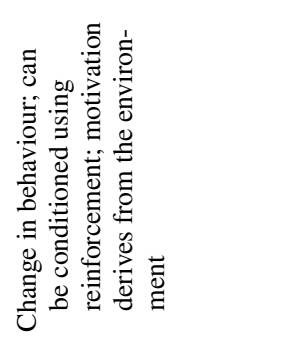 & 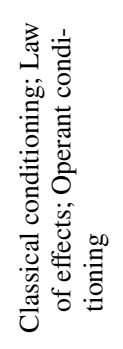 & 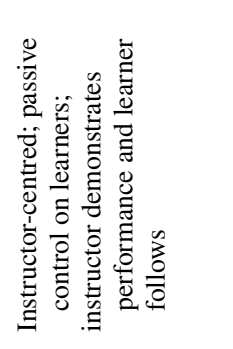 & 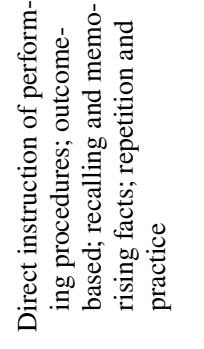 \\
\hline 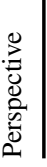 & 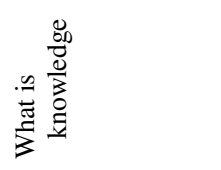 & 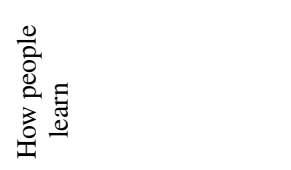 & 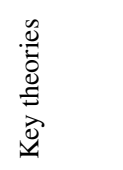 & 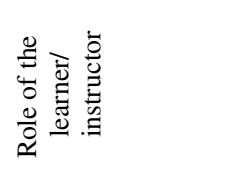 & 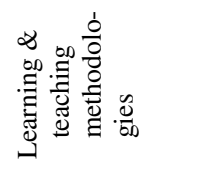 \\
\hline
\end{tabular}




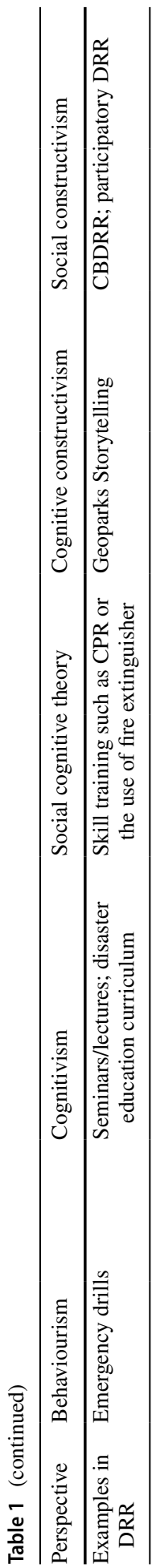




\subsubsection{Behavioural approaches to DRR activities}

Explicit links to behaviourism are not been made in the existing DRR literature, but emergency drills can be regarded as the major example of behavioural activities in the context of DRR. As Preston (2012, p. 5) puts it: 'Rehearsal is used to routinise and familiarise individuals and families with preordained rules of behaviour'. 'Drop, cover and hold (on)' in time of an earthquake is the key 'rule' shared worldwide, and people rehearse or drill the action of dropping, covering and holding in various settings. This rule aims to establish a stimulus-response relationship-when there is a tremor-stimulus-you must cover and hold-response. Many governments of quake-prone countries consider 'Drop, cover and hold' to be 'the appropriate action to reduce injury and death during earthquakes' (Southern California Earthquake Center 2020a), urging the populations to learn what to do during an earthquake (Mahdavifar et al. 2009; New Zealand National Emergency Management Agency 2020a; Southern California Earthquake Center 2020b). The same principle of stimulus-response applies in tsunami evacuation drills, which aim to establish behaviour-if there is an evacuation order, you evacuate. Whether at school, work or in the neighbourhood, a drill in the normal time is conducted to practise the event of evacuation following the instruction of which route to take to arrive at the evacuation area within the given time. The drill is repeated to establish stimulus-response. Particularly since the 2004 Indian Ocean tsunami and the 2011 Tohoku tsunami, many governments have developed better early warning systems and evacuation plans. For these measures to work effectively, a number of experts have emphasised the significance of investments in DRR education, including drilling exercises (Esteban et al. 2013; Mikami et al. 2014).

The major critique of behavioural approaches was they neglect learners' inner motivation, thoughts and emotions, which led to the emergence of cognitivism. In an emergency which requires immediate action to protect oneself, learning to respond to a stimulus without involving thinking and feeling appears to serve the purpose. There remains a question of a reward. Drills are hypothetical scenarios, but positive reinforcement could still be made by, for example, timing the evacuation or offering positive feedback.

\subsection{Cognitivism}

Cognitive science, particularly human and computer sciences, began taking shape in the 1960s as an opposition to behaviourism (Weibell 2011). Cognitivism views knowledge exits outside of the person but considers knowledge acquisition as information processing rather than memorising and repetition. Learning, therefore, is a mental activity which is an internal process of thinking, understanding and organising information. Previous experiences and existing knowledge play a large part in the process of learning (Sternberg and Williams 2010; Bohlin et al. 2012). Cognitivists studied perception, as well as how knowledge is acquired, stored and used (Weibell 2011). Atkinson and Shiffrin pioneered the 'information processing' model, which refers to the three-stage memory storage of sensory register, short-term memory and long-term memory (Atkinson and Shiffrin 1968). As a critique of the information processing model, Ausubel argued for 'meaningful learning' (Ausubel 1962). For effective learning, 'assimilation' has to happen (Ausubel et al. 1978). It indicates the integration of new information into the learner's existing cognitive structure-what she/he already knows. For Gagné, learning was more than assimilation. 
Gagné asserted there are different types of learning and learning outcomes, each of which requires a specific instructional design. He introduced a common set of steps. His 'cumulative learning' theory asserted knowledge and skills have a hierarchy, and learning follows from a lower- to a higher-order (Gagné 1985).

Cognitivism is instructor-centred in a way that the information is transmitted from someone who knows (i.e. instructor, expert) to those who do not know (i.e. learner, novice). The difference from behaviourism is the instructor organises the content to suit the learner's levels and needs, with tools and aids, and the learner actively processes the content. The expert-novice division is clear, even though learners' active engagement is a requisite in achieving learning (Ausubel et al. 1978; Schunk 2012). Expert-novice methodologies involve support tools, such as 'advance organizers' introduced by Ausubel (1962), which aim to provide learners appropriate 'subsumers' in advance of the main task. 'The nine events of instructions' proposed by Gagné (1985) address the different types of learning and learning outcomes mentioned above. The standard nine steps begin with 'Gain attention', 'Inform learners of objectives' and end with 'Enhance retention and transfer to the job', which were based on empirical studies on the instructional procedures and the information-processing model of learning. The nine events of instructions are widely applied in various learning contexts to the present date as a starting point for every type of learning, including problem-solving, learning through inquiry and peer learning (Eggen and Kauchak 2013; Santrock 2018).

\subsubsection{Cognitivist approaches to DRR activities}

DRR experts have developed and implemented a wide range of cognitivist activities, even though no explicit reference to cognitivism is made. One example is DRR seminars or lectures providing the audience with specialised knowledge and skills in a given educational setting whether at a school, university or public forum. How far the content of the input is structured may vary. There may also be a limitation to achieving 'meaningful learning' through a one-off seminar. The common goal, however, is for the audience to process the information, understand it, remember it and use it when needed. The likeliness is the more formal the setting is, the more structured the content becomes. In some countries, disaster education curriculum is available, even though it is not necessarily a compulsory subject. New Zealand has a voluntary curriculum-based platform called 'What's the Plan, Stan?' for teaching disaster preparedness in primary schools (New Zealand National Emergency Management Agency 2020b). The comprehensive teaching and learning resources are divided into different year groups, aiming for acquiring scientific knowledge of hazards and raising preparedness awareness. Specific advice is offered to teachers, in which cognitive methodology can be identified: 'Link new information to prior knowledge and learning' and 'Understanding how the science of natural events links to the social impacts in your local area creates many opportunities to create learning pathways' (New Zealand National Emergency Management Agency 2020b).

Public seminars, university lectures and disaster education at school are based on instructor-centred and expert-novice methodologies. The speaker, lecturer or teacherexpert-pass knowledge and skills to the audience or pupils-novice-who process the received information and assimilate it into their existing knowledge-base. 'What's the Plan, Stan?' may have referenced Gagné's instructional design to enable 'cumulative learning' starting from basic to complex knowledge. Teachers in New Zealand are highly likely to have planned lessons taking their pupils' levels and needs into consideration with the use 
of teaching tools and learning aids. There is an evaluation study of the implementation of 'What's the Plan, Stan?', which concludes the inconsistency in the implantation of the national strategy (Johnson et al. 2014). The teachers who used the resource were satisfied with its usefulness, but many needed more assistance and guidance in utilising the resource fitting into the existing curriculum activities (Johnson et al. 2014). Cognitivist approaches hence have a reliance on instructors' capabilities.

\subsection{Social cognitivism theory}

This is Bandura's (1986) theory, which encompasses both behavioural and cognitive characteristics. This paper treats it independently from either because of its duality. Bandura initially called the theory 'social learning theory' (Bandura 1977). As discussed earlier, the origin of 'social learning' is here, but it has branched out into multiple versions. Bandura shifted his position across 30 years of his career-from a behavioural alignment (Bandura 1977) to a cognitive preference (e.g. Bandura 1996, 1986) and towards an agentic perspective of social cognitive theory (e.g. Bandura 2001) and towards a psychology of human agency (e.g. Bandura 2006a) (Weibell 2011). Thus, it is hard to fit Bandura under one perspective. Bandura himself explains social cognitive theory synthesises concepts and processes from behavioural and cognitive thinkings: 'the social portion of the title acknowledges the social origins of much human thought and action; the cognitive portion recognizes the influential contribution of cognitive processes to human motivation, affect, and action' (Bandura 2006b, p. 65).

\subsubsection{DRR activities applying social cognitive theory}

Social cognitive theory involves many key concepts. The foundation concept is 'triadic reciprocality', which indicates reciprocal interactions between personal, behavioural and environmental factors (Bandura 1986, 1996). In addition to behavioural views that the environment determines behaviour, social cognitive theory advocates that behaviour also determines the environment and that personal cognition influences both behaviour and the environment. The reciprocality is applied in further concepts of learning. Social cognitive theory includes learning through actual doing, but also learning from the consequences of the doing - this is called 'enactive learning'. People generally wish to learn behaviours that match their values and beliefs and that have desirable consequences. 'People's cognitions, rather than consequences, affect learning (Schultz 2013, p. 121)'. Bandura saw much of learning occurs through observation. 'Observational learning', comprising four processes (attention, retention, reproduction, motivation), occurs by watching or modelling others' behaviours. There are three kinds of models- 'live' (a behaviour in person), 'verbal' (by explanation) and 'symbolic' (Internet sources, films, books) (Bandura 1986; Zimmerman and Schunk 2003). Observational learning can happen with 'vicarious reinforcement' (Bandura et al. 1963; Bandura 1996) through verbal and symbolic models. Bandura (2001; 2006a) also discussed efficacy and agency in both individual and collective senses. Efficacy is one's belief that she/he can achieve the set goal or produce wanted outcomes. Efficacy then determines agency. If one does not have the belief, there is little motivation to make an action. The same mechanism applies in a group context. Bandura believed human beings do not live in isolation, and 'interdependent efforts' are necessary for achieving most of what they wish to achieve. This is where 'collective agency' is exercised amongst those who share a common goal, leading to collective action. 
The role of the instructor is a model in social cognitive theory, from whom the learner obtains an understanding of how to perform. 'The instructor' is not necessarily a person in vicarious learning. Methodologies are focused around observation and performance. Sports can be a helpful setting. A coach explains and demonstrates the theories and techniques of the sport, the learner observes, practices and also responds to the coach's feedback. The learner may learn from watching professional players perform perfectly. Social cognitive learning involves setting goals, judging anticipated outcomes of actions, evaluating progress toward goals (feedback) and self-regulating thoughts, emotions and actions (self-evaluation) (Weibell 2011; Schultz 2013).

As discussed earlier, 'social learning' is gaining a stake in DRR research, however, a clear application of Bandura's social cognitive theory cannot be found. What this paper can suggest is certain DRR activities have certain aspects of social cognitive theory. Training, workshops and events in which acquisition of physical skills takes place, such as how to undertake cardiopulmonary resuscitation (CPR) or how to use a fire distinguisher, have the features of enactive observational learning. Learning by modelling is a powerful means of perfecting performative skills (Aliakbari et al. 2015). An expert instructor demonstrates the correct skills, and learners imitate and practise them until they receive affirmation from the instructor. Learners can vicariously develop cognitive preparedness and resilience through reading or watching DRR leaflets and videos.

Vicarious experience may also happen by simply observing others' disaster experiences. 'The miracle of Kamaishi' is a good example of that. All pupils from Kamaishi Elementary School survived the 2011 Tohoku tsunami. They had been taught tsunami tendenko and trained to protect themselves in case of a tsunami. The Tohoku dialect indicates, if you see a tsunami approaching, run towards a higher ground on your own without relying on others, trusting your family and friends are fine' (Yamori 2012). Kamaishi was compared with other schools that lost many pupils due to not making their own decision to evacuate. 'The miracle of Kamaishi' was vicarious learning for the rest of Japan-without experiencing the tsunami and evacuation, both experts and laypersons learned the criticality of tsunami tendenko. It was re-evaluated and became the central strategy in tsunami preparedness.

\subsection{Constructivism}

Constructivism established by the 1980s saw knowledge as construction. Aiming to clarify the relationship between human experience and the creation of knowledge, constructivism focuses on the integration of skills and knowledge in the real world. Constructivism had a significant impact on various disciplines in social science with two branches: cognitive constructivism focuses on individuals, while social constructivism focuses on groups (McInerney and McInerney 2002; Schultz 2013; Santrock 2018).

\subsubsection{Cognitive constructivism}

Knowledge is constructed by the person through her/his cognitive process interpreting the information from the environment, including other people. The interpretation varies depending on personality, beliefs, cultures and experiences. Such subjective representations of objective reality become knowledge. Learning is constructed by the learner. This means learning is unique based on individual mental models and prior knowledge structures. The incoming information is not automatically received but processed through the pre-existing mental structures. Learning is strongly associated with discovery and hence 
requires self-regulation. Learning also takes the forms of the building of conceptual structures through reflection and abstraction (Weibell 2011; Schunk 2012; Lefrançois 2019). One of the most influential constructivist theorists is Dewey (1933). The educational philosopher advocated 'progressive education' to modify the traditional approaches to teaching and learning (Schunk 2012). He argued that education at school was detached from real-world situations and that children should be taught how to think rather than memorising facts. Learning by doing, often referred to as 'experiential learning' (Kolb 1984), is at the heart of progressive education. An educational psychologist Piaget proposed 'cognitive development' theory based on his belief that mental growth and physical growth were inseparable. He proposed four developmental stages that represent a linear progression from 'spontaneous movements and reflexes' in the 'sensorimotor' and 'preoperational' stages, to acquire habits in the 'concrete operational' stage and to acquire intelligence in the 'formal operational' stage (Piaget and Inhelder 1969, p. 5). Bruner was in line with developmental learning but believed children are capable of understanding complex ideas when they are introduced in an organised and supported way. He is known for 'learning through discovery' - 'discovery' does not necessarily mean invention, but obtaining knowledge though personal exploration (Bruner 1960, 1961).

The learner takes an active role in constructing her/his understanding, and thus learnercentredness is the principle. Rather than receiving it from someone who knows, the learner proactively engages in observation, processing and interpretation of the new content. This means the instructor has the role of a facilitator (McInerney and McInerney 2002; Yardley et al. 2012; Eggen and Kauchak 2013). The emphasis of methodologies is on the activity of the learner during the construction of knowledge, such as discovery learning, exploratory learning and peer learning. Experiential learning emphasises hands-on activities and field projects enable learners to prepare for the real world where teamwork, critical thinking, creativity and the ability to work independently are required (Yardley et al. 2012; Kolb 2015). Bruner's (1960) 'spiral curriculum' is a structure for teaching complex ideas, which starts with introducing the simplified version of the ideas and later on, returning to more complex versions of them. Bruner also recommended 'scaffolding' (Wood et al. 1976) as a teaching and learning methodology. It refers to consecutive organised support for learners to achieve the next levels of knowledge and skills acquisition. As the metaphor implies, the instructor gradually removes the support until the learner gains independence in the learning process.

\subsubsection{Social constructivism}

Social constructivism views knowledge is a social production based on how a person interacts with others and experiences environments. Social and cultural exchanges within the environment in which children grow up determine thinking and behaviour. Learning is social and cultural and through exchanges and interactions. Learning is understood as the process through which the learners are integrated into a learning community, not merely as the assimilation of new information. The learning community is context-specific, in which the process of collaboration becomes the key to achieving quality learning. Learning can be an incidental outcome that accompanies these social processes (Eggen and Kauchak 1999; McInerney and McInerney 2002; Santrock 2018). While Piaget's position was cognitive development being almost universal, Vygotsky argued the interaction of interpersonal (social), cultural-historical and individual factors determines human development (Scrimsher and Tudge 2003). He considered a language, which is part of the culture, plays a 
central role in learning, because learning occurs through 'collaborative dialogue' to enable social interactions with family and friends, peers or neighbours. The dialogue is particularly significant in 'the zone of proximal development (ZPD)' (Vygotsky 1978). One can reach some goals without help but can only achieve certain areas when there is support from 'more knowledgeable others' - e.g. a skilful teacher, digital sources. ZPD refers to the situation of the latter. Taking Vygotsky's position further, Lave and Wenger (1991) developed the theory of 'situated learning' through 'legitimate peripheral participation (LPP)' in 'communities of practice'. They view 'learning' as 'increasing participation in communities of practice' which involves 'the whole person acting in the world' (Lave and Wenger 1991, p. 49). Their focus is on the structure of social practice in which learning occurs, not on curriculum and pedagogy. The concept of LPP is 'an analytical viewpoint on learning, a way of understanding learning' (Lave and Wenger 1991, p. 40). Learning indicates 'a relation to social communities', moving from 'peripheral participation' towards 'full participation' (Lave and Wenger 1991, p. 49). The legitimacy of participation lies in the ways of belonging to the community. 'Peripheral' indicates the inclusive nature of 'participation' defined by the community. Wenger later offered a clear definition of 'communities of practice': they are 'groups of people who share a concern or a passion for something they do and learn how to do it better as they interact regularly' (Wenger 2009).

A group of participants are the learners, who are members of society. A facilitator or an organiser might support the group as a 'more knowledgeable other' in ZPD, but the mode of her/his instruction is constructive rather than top-down. The relationship between them tends to be collaborative, aiming for co-construction of knowledge (Eggen and Kauchak 1999; Scrimsher and Tudge 2003). 'A community of practice is not merely a club of friends or a network of connections between people. It has an identity defined by a shared domain of interest (Wenger 2009)'. Membership is fostered through participation and commitment. Methodologies value proactive participation to enable active learning of the learner. A group of people who have a common interest in a subject collaborate over a certain period, sharing ideas/strategies to determine solutions and build innovations. They support each other, share information and 'build relationships that enable them to learn from each other' (Wenger 2009). Thus, the emphasis is on the whole rather than components. 'More knowledgeable others' may help novice learners to progress in gaining knowledge and skills. Interactions in the environment, whether in apprenticeships or collaborative projects, stimulate developmental processes and foster cognitive growth. Discussion groups, workshops or scaffolding learning in which learners actively participate exchanging different views against a subject are prevalent methods (McInerney and McInerney 2002; Scrimsher and Tudge 2003; Thomas et al. 2014; Aliakbari et al. 2015).

\subsubsection{Cognitive constructivist approaches to DRR activities}

Cognitive constructive approaches involve learning by doing, discovery learning and peer learning. UNESCO Global Geoparks (UNESCO 2020a), of which number is currently 147 in 41 countries, can be considered as one. Geoparks are 'unified geographical areas where sites and landscapes of international geological significance are managed with a holistic concept of protection, education and sustainable development' (UNESCO 2020a). The idea of geoparks derived from the realisation of the need for broad knowledge-base and preparedness enhancement as one of the responses to 'the devastating destructions' caused by catastrophic events such as the 2004 Sumatra and the 2011 Tohoku earthquakes and tsunamis (Fassoulas et al. 2018). 'Education about our dynamic planet is the most effective 
way to help our local communities to coexist in accordance with our risky nature'; thus, geoparks should 'utilize the experience of local communities and of the destruction that occurred as a tool for the education in geo-hazard prone areas of the Earth' (Fassoulas et al. 2018, p. 179). Visiting an actual geosite differs from learning from books or visual aids. In addition to organised learning opportunities, tourist-learners are also a target in 'geotourism', which is to promote sustainable local economic development (UNESCO 2020b). Tourists visit to enjoy, appreciate and engage in geosites, but also to learn from them about both 'forms' (e.g. landforms, sediments) and 'processes' (e.g. volcanism, erosion) of geology (Dowling 2011).

Storytelling for DRR can also be understood through cognitive constructivism. As Bruner (1991) indicates, a story, or a narrative, is a powerful instrument which helps develop cognitive knowledge, as well as a useful cognitive tool to support the learner during the meaning construction (Bruner 1991). Three uses of storytelling can be identified concerning DRR: storytelling as a resource for preparedness (e.g. Gu 2011; Gaeta et al. 2014; Hou 2019), a means for personal recovery (e.g. Lindahl 2012; Carlin and Park-Fuller 2012; Kargillis et al. 2014a) and as a remembrance/legend/oral history for awareness-raising (e.g. Takano and Atsumi 2007; Lindahl 2012). The first group tends to involve developing a digital simulation of disaster scenarios with the use of technologies so that the learner(s) obtain the knowledge and skills to self-help in real situations. The second group is talking therapy to recognise and convey the emotional impact of survivors in post-disaster contexts. According to Harvey (1996), accepting and facing pain could help survivors become stronger. The storyteller recovers from the pain by telling her/his observation and interpretation of the disaster and its impacts, which is a cognitive constructivist process. Research shows storytelling contributes to raising awareness and building social capital amongst the audience (Harvey 1996; Kargillis et al. 2014b). This suggests storytelling entails social constructivist aspects as well, which is the third group's focus. They intend to share the story for it to be remembered.

Learner-centredness is the core principle of cognitive constructivist approaches. Geoparks offer an opportunity for the learner to construct a piece of new knowledge about the geology and the site through her/his cognitive process of the information provided and hands-on experience in the park. In this light, natural science museums, memorial museums and field studies also share the same principles. The instructor or expert is present as a facilitator to support gradual learning-scaffolding - of learners. Storytellers construct their knowledge through recalling, reflecting and recording their own experiences. There may be an expert facilitator supporting this process. The audience of the story also constructs their knowledge through listening and comprehending the storyteller's experience and thoughts and simultaneously reflecting on their own behaviours and perceptions.

\subsubsection{Social constructivist approaches to DRR activities}

This paper suggests that DRR activities based on social constructivism are expanding because of the growing emphasis on community-based, bottom-up or participatory approaches in co-constructing DRR knowledge and practice (Kitagawa 2019c). The studies around community and participation tend to be intervention projects funded by governments, donors, researchers, businesses, or the combination amongst them. Compared to these, the studies on self-organised activist groups, which are grassroots informal groups aiming to resolve forgotten issues in the communities are smaller in numbers (Seebauer et al. 2019). Both types of studies do not always refer social constructivism, but mostly, its 
certain features are identifiable in the target DRR activities, i.e. community members or participants having 'a shared domain of interest', and LPP in forming communities of practice (e.g. Murphy 2007; Dittrich et al. 2016; Tanwattana 2018; Samaddar et al. 2018, 2019; Li and Tan 2019). McEwen et al.'s (2018) study on action flood groups in England looks at an intervention programme based on a 'co-working model' having a civil agency as an intermediary between government authorities and citizens. The intermediary agency is a voluntary organisation in itself but with more expertise and resources playing a facilitating and empowering role for communities. The study demonstrates the learning journeys from peripheral towards full participation of the members of two newly formed action groups. In the beginning, collaboration was hard for the group members and the facilitator from the intermediary agency - a more knowledgeable other. 'Hot-headedness' of certain members and 'less-vocal' members were normalised within the participatory process achieving 'constructive dialogue' (McEwen et al. 2018, p. 334). There is a clear indication that the DRR activity they studied has a social constructivist perspective, even though McEwen et al. themselves position their study in the realm of 'social learning'.

One example that does connect DRR activities and a learning theory deploy LPP and communities of practice in implementing collaborative DRR (e.g. Shiroshita and Yamori 2011; Iwahori et al. 2017). They argue that expert researchers are part of 'a community of practice' (Lave and Wenger 1991), supporting laypersons' 'legitimate peripheral participation', aiming for their full participation exercising agency. Iwahori et al. (2017), for example, studied a project which aimed to convert a seismological observatory into a disaster science museum in Japan based on the collaboration between expert seismologists and non-expert volunteers. The study identifies the shift in volunteers' identity from novice volunteers-peripheral participation to 'semiexperts' - towards full participation in the joint venture (Iwahori et al. 2017).

Social constructivist approaches define learning quite differently from other perspectives. Learning is social, cultural and communal, and no longer belongs to one individual. Learning derives from 'a common interest', such as flood preparedness or the creation of a disaster science museum. It is pursued through interactions and collaborations amongst the group members, and therefore, a sense of belonging and a membership identity develop. The collective goal is more emphasised than the individuals' interests. Expert-novice differences are not necessarily emphasised, and in fact, some research aims to eliminate the expert-novice boundary as described above. Considering DRR activities using social constructivist perspectives is relevant, given the growth of the research and literature examining as community-based, bottom-up or participatory approaches to DRR.

\section{Conclusion}

Three tentative conclusions can be drawn from this study. First, it has confirmed the limited reference to learning perspectives and theories in DRR literature. Except for the case of LPP and communities of practice discussed above, the foci of the studies of DRR activities have been what people should learn, rather than how people learn. Engagement with learning perspectives and theories will allow conceptualising how people learn to be prepared and resilient, which will then benefit disaster risk management planning. Social learning is a promising area. Drawing on the definitions and frameworks being developed in the field of environmental management, DRR research could tease out the process and outcome of public participation. 
Second, it may not be straightforward to associate a DRR activity with one learning perspective. Returning to the example of storytelling, it may be initially designed as a cognitive constructivist activity but entails a social constructivist aspect when the story is shared with others. An overall tendency for a disaster education curriculum at school may be cognitivism, but the curriculum is likely to include a variety of activities such as group discussions and field trips. Emergency drills are behavioural, but before practising the drills, there may be cognitive lessons to explain what a tsunami is. Thus, the paper recognises the complexities of linking DRR activities with learning. Nonetheless, the argument here is the potential usefulness of learning perspectives and theories in DRR research.

The third point is about the recent emphasis on community-based DRR and participatory approaches. The democratic methodology is certainly significant. Currently, however, there seems to be too much reliance on the methodology as if it is a panacea. All DRR activity examples discussed in this paper have a particular role to play: through a repetitive evacuation drill, people develop a reflex so that they can act immediately when they are aware of the risk; in visiting a geopark, people gain an understanding of, for instance, the volcano through sensory as well as cognitive experiences; people can vicariously learn to manage risks by watching documentary programmes or from Internet sources. How a community or an institution could 'pick and mix' activities to meet their needs maybe the question to ask.

Two learning perspectives this paper did not discuss could also have a role to play in DRR. Humanism values the totality of human existence as a free person and maximising human potential. There are a few examples (Chadderton 2015; Kitagawa 2016) that relate DRR activities with lifelong learning, which is one of the branches of humanism. Connectivism represents 'digital age learning', which is about how Internet technologies create new opportunities for people to learn and share information (Siemens 2005). Jung et al. (2013), for example, examine community media connectedness in a post-disaster context. Connectivism has relevance in the 21 st-century DRR activities.

Funding The funding was provided by University College London (UCL).

Open Access This article is licensed under a Creative Commons Attribution 4.0 International License, which permits use, sharing, adaptation, distribution and reproduction in any medium or format, as long as you give appropriate credit to the original author(s) and the source, provide a link to the Creative Commons licence, and indicate if changes were made. The images or other third party material in this article are included in the article's Creative Commons licence, unless indicated otherwise in a credit line to the material. If material is not included in the article's Creative Commons licence and your intended use is not permitted by statutory regulation or exceeds the permitted use, you will need to obtain permission directly from the copyright holder. To view a copy of this licence, visit http://creativecommons.org/licenses/by/4.0/.

\section{References}

Aliakbari F, Parvin N, Heidari M, Haghani F (2015) Learning theories application in nursing education. J Educ Health Promot. https://doi.org/10.4103/2277-9531.151867

Atkinson RC, Shiffrin RM (1968) Human memory: a proposed system and its control processes. In: Spence KW, Spence JT (eds) Psychology of learning and motivation. Academic Press, Amsterdam, pp 89-195

Ausubel DP (1962) A subsumption theory of meaningful verbal learning and retention. J Gen Psychol 66:213-224. https://doi.org/10.1080/00221309.1962.9711837 
Ausubel DP, Novak JD, Hanesian H (1978) Educational psychology: a cognitive view, 2d edn. Holt, Rinehart and Winston, New York

Bandura A (1977) Social learning theory. Prentice Hall, New Jersey

Bandura A (1996) Social cognitive theory of human development. In: Husen T, Postlethwaite TN (eds) International encyclopedia of education. Pergamon Press, Oxford, pp 5513-5518

Bandura A (1986) Social foundations of thought and action: a social cognitive theory. Prentice-Hall Inc, Englewood Cliffs, NJ, US

Bandura A (2001) Social cognitive theory: an agentic perspective. Annu Rev Psychol 52:1-26. https://doi. org/10.1146/annurev.psych.52.1.1

Bandura A (2006a) Toward a psychology of human agency. PerspectPsycholSci 1:164-180. https://doi.org/1 0.1111/j.1745-6916.2006.00011.x

Bandura A (2006b) Autobiography. In: Lindzey MG, Runyam WM (eds) A history of psychology in autobiography, vol IX. American Psychological Association. Washington, D. C., pp 42-75

Bandura A, Ross D, Ross SA (1963) Vicarious reinforcement and imitative learning. J AbnormSocPsychol 67:601-607. https://doi.org/10.1037/h0045550

Benson D, Lorenzoni I, Cook H (2016) Evaluating social learning in England flood risk management: an 'individual-community interaction' perspective. Environ Sci Policy 55:326-334. https://doi. org/10.1016/j.envsci.2015.05.013

Bohlin L, Durwin CC, Reese-Weber M (2012) Edpsych: modules, 2nd edn. McGraw-Hill Humanities/ Social Sciences/Languages, New York

Bruner J (1991) The narrative construction of reality. CritInq 18:1-21. https://doi.org/10.1086/448619

Bruner JS (1960) The process of education. Harvard Univer, Press, Oxford, England

Bruner JS (1961) The act of discovery. Harvard Educational Review 31:21-32

Carlin PS, Park-Fuller LM (2012) Disaster narrative emergent/cies: performing loss, identity and resistance. Text Perform Q 32:20-37. https://doi.org/10.1080/10462937.2011.622782

Chadderton C (2015) Civil defence pedagogies and narratives of democracy: disaster education in Germany. Int J Lifelong Educ 34:589-606. https://doi.org/10.1080/02601370.2015.1073186

Cundill G, Rodela R (2012) A review of assertions about the processes and outcomes of social learning in natural resource management. J Environ Manage 113:7-14. https://doi.org/10.1016/j.jenvm an.2012.08.021

Dittrich R, Wreford A, Butler A, Moran D (2016) The impact of flood action groups on the uptake of flood management measures. Clim Change 138:471-489. https://doi.org/10.1007/s1058 4-016-1752-8

Dowling RK (2011) Geotourism's global growth. Geoheritage 3:1-13. https://doi.org/10.1007/s1237 1-010-0024-7

Eggen PD, Kauchak DP (1999) Educational psychology: windows on classrooms. Merrill Publisher, London

Eggen PD, Kauchak DP (2013) Educational psychology: windows on classrooms, 9th edn. Peason, Upper Saddle River, N.J.

Esteban M, Tsimopoulou V, Mikami T et al (2013) Recent tsunamis events and preparedness: development of tsunami awareness in Indonesia, Chile and Japan. Int J Disaster Risk Reduct 5:84-97. https://doi.org/10.1016/j.ijdrr.2013.07.002

Fassoulas C, Watanabe M, Pavlova I, et al (2018) UNESCO Global Geoparks: living laboratories to mitigate natural induced disasters and strengthen communities' resilience. In: Natural hazards and disaster risk reduction policies. Il Sileno Edizioni, pp 175-197

Fisher S, Dodman D (2019) Urban climate change adaptation as social learning: exploring the process and politics. Environ Policy Gov 29:235-247. https://doi.org/10.1002/eet.1851

Gaeta M, Loia V, Mangione GR et al (2014) A methodology and an authoring tool for creating complex learning objects to support interactive storytelling. Comput Hum Behav 31:620-637. https://doi. org/10.1016/j.chb.2013.07.011

Gagné RM (1985) The conditions of learning and theory of instruction. Holt, Rinehart and Winston, New York

Gu H (2011) Design of disaster education courseware based on digital storytelling. In: Proceedings of the 2011 third international workshop on education technology and computer science. 01. IEEE Computer Society, USA, 673-675

Harvey JH (1996) Embracing their memory: loss and the social psychology of storytelling. Allyn \& Bacon, Needham Heights, MA, US

Henly-Shepard S, Gray SA, Cox LJ (2015) The use of participatory modeling to promote social learning and facilitate community disaster planning. Environ Sci Policy 45:109-122. https://doi. org/10.1016/j.envsci.2014.10.004 
Hou JZ (2019) Unlocking the power of digital storytelling for community resilience building in disaster risk communication: a case study from Australia. In: 2019 International association of media and communication research (IAMCR) conference

Illeris K (ed) (2009) Contemporary theories of learning: learning theorists ... in their own words, 1 st edn. Routledge, London

Iwahori T, Yamori K, Miyamoto T et al (2017) Disaster education based on legitimate peripheral participation theory: a new model of disaster science communication. J Nat Disaster Sci 38:15

Jackson NJ (2011) Learning for a complex world: a lifewide concept of learning. Education and Personal Development, AuthorHouse

Johansson M, Nyberg L, Evers M, Hansson M (2013) Using education and social learning in capacity building - the IntECR concept. Disaster PrevManag 22:17-28. https://doi.org/10.1108/09653 561311301943

Johnson VA, Ronan KR, Johnston DM, Peace R (2014) Implementing disaster preparedness education in New Zealand primary schools. Disaster PrevManag 23:370-380. https://doi.org/10.1108/ DPM-09-2013-0151

Jung J-Y, Toriumi K, Mizukoshi S (2013) Neighborhood storytelling networks, internet connectedness, and civic participation after the Great East Japan earthquake. Asian J Commun 23:637-657. https ://doi.org/10.1080/01292986.2013.819930

Kargillis C, Gillham D, Kako M (2014) Disaster survivors: a narrative approach towards emotional recovery. Aust J EmergManag 29:25

Kay D, Kibble J (2016) Learning theories 101: application to everyday teaching and scholarship. AdvPhysiolEduc 40:17-25. https://doi.org/10.1152/advan.00132.2015

Kitagawa K (2017) Situating preparedness education within public pedagogy. Pedag, Culture Soc 25:113. https://doi.org/10.1080/14681366.2016.1200660

Kitagawa K (2019a) Questioning 'integrated' disaster risk reduction and 'all of society' engagement: can 'preparedness pedagogy' help? Comp: J Comp IntEduc 49:851-867. https://doi. org/10.1080/03057925.2018.1464385

Kitagawa K (2019b) Exploring 'everyday-life preparedness': three case studies from Japan. Int J Disaster Risk Reduct 34:265-274. https://doi.org/10.1016/j.ijdrr.2018.11.025

Kitagawa K (2019c) Co-constructing a narrative of 'never give up' in preparing for a mega-tsunami: an exemplar of 'all-of-society engagement'? Geosciences 9:486. https://doi.org/10.3390/geoscience s9120486

Kitagawa K (2016) Disaster preparedness, adaptive politics and lifelong learning: a case of Japan. Int J Lifelong Educ 35:629-647. https://doi.org/10.1080/02601370.2016.1231230

Kitagawa K, Preston J, Chadderton C (2017) Preparing for disaster: a comparative analysis of education for critical infrastructure collapse. J Risk Res 20:1450-1465. https://doi.org/10.1080/13669 877.2016.1178661

Kolb DA (1984) Experiential learning: experience as the source of learning and development. PrenticeHall, Englewood Cliffs, N.J.

Kolb DA (2015) Experiential learning: experience as the source of learning and development, 2nd edn. Pearson Education Inc, Upper Saddle River, New Jersey

Lave J, Wenger E (1991) Situated learning: legitimate peripheral participation. Cambridge University Press, New York, NY, US

Lefrançois GR (2019) Theories of human learning. Cambridge University Press, Cambridge

Li Z, Tan X (2019) Disaster-recovery social capital and community participation in earthquake-stricken Ya' an areas. Sustainability 11:993. https://doi.org/10.3390/su11040993

Lindahl C (2012) Legends of hurricane katrina: the right to be wrong, survivor-to-survivor storytelling, and healing. J Am Folk 125:139-176. https://doi.org/10.5406/jamerfolk.125.496.0139

Lindell MK, Perry RW (2012) The protective action decision model: theoretical modifications and additional evidence. Risk Anal 32:616-632. https://doi.org/10.1111/j.1539-6924.2011.01647.x

Mahdavifar MR, Izadkhah YO, Heshmati V (2009) Appropriate and correct reactions during earthquakes: "Drop, Cover and Hold on" or "Triangle of Life". J Seismology Earthq Eng 11:41-48

McCaughey JW, Mundir I, Daly P et al (2017) Trust and distrust of tsunami vertical evacuation buildings: extending protection motivation theory to examine choices under social influence. Int J Disaster Risk Reduct 24:462-473. https://doi.org/10.3929/ethz-b-000192557

McEwen L, Holmes A, Quinn N, Cobbing P (2018) 'Learning for resilience': developing community capital through flood action groups in urban flood risk settings with lower social capital. Int J Disaster Risk Reduct 27:329-342. https://doi.org/10.1016/j.ijdrr.2017.10.018

McInerney DM, McInerney V (2002) Educational psychology: constructing learning. Prentice Hall, Frenchs Forest 
Mikami T, Shibayama T, Esteban M et al (2014) Tsunami vulnerability evaluation in the Mentawai islands based on the field survey of the 2010 tsunami. Nat Hazards 71:851-870. https://doi. org/10.1007/s11069-013-0936-Z

Muro M, Jeffrey P (2008) A critical review of the theory and application of social learning in participatory natural resource management processes. J Environ Plan Manage 51:325-344. https://doi. org/10.1080/09640560801977190

Murphy BL (2007) Locating social capital in resilient community-level emergency management. Nat Hazards 41:297-315. https://doi.org/10.1007/s11069-006-9037-6

Murti R, Mathez-Stiefel S (2019) Social learning approaches for ecosystem-based disaster risk reduction. Int J Disaster Risk Reduct 33:433-440. https://doi.org/10.1016/j.ijdrr.2018.09.018

Murti R, Mathez-Stiefel S-L, Garcia VR, Rist S (2020) Engaging national policy makers in ecosystem based disaster risk reduction through social learning: lessons from workshops in Africa, oceania, Latin America and the Caribbean. Int J Disaster Risk Reduct 45:101463. https://doi.org/10.1016/j. ijdrr.2019.101463

Neuwirth K, Dunwoody S, Griffin RJ (2000) Protection motivation and risk communication. Risk Anal 20:721-734. https://doi.org/10.1111/0272-4332.205065

New Zealand National Emergency Management Agency (2020a) In an emergency: Earthquakes. In: Get Ready - Emergency Preparedness in New Zealand. https://getready.govt.nz/emergency/earthquake s/. Accessed 13 Apr 2020

New Zealand National Emergency Management Agency (2020b) What's the Plan Stan? In: Get Ready Emergency preparedness in New Zealand. https://getready.govt.nz/prepared/school/whats-the-planstan/. Accessed 17 May 2020

Nguyen QA, Hens L, MacAlister C et al (2018) Theory of reasoned action as a framework for communicating climate risk: a case study of schoolchildren in the Mekong Delta in Vietnam. Sustainability 10:2019. https://doi.org/10.3390/su10062019

O’Donohue W, Kitchener R (eds) (1999) Handbook of behaviorism. Academic Press, San Diego, CA, US

Okumoto K (2010) Lifelong learning policy in England and Japan: a comparative analysis. LAP Lambert Academic Publishing, Germany

Pahl-Wostl C (2006) The Importance of social learning in restoring the multifunctionality of rivers and floodplains. EcolSoc. https://doi.org/10.5751/ES-01542-110110

Paton D (2008) Community resilience: Integrating individual, community and societal perspectives. In: The phoenix of natural disasters: community resilience. Nova Science Publishers13-31, New York, pp 13-31

Paton D (2003) Disaster preparedness: a social-cognitive perspective. Disaster PrevManag: An Int J 12:210216. https://doi.org/10.1108/09653560310480686

Paton D, Jang LJ (2012) Increasing community potential to manage earthquake impacts: the role of social and cultural factors. Earthquakes: triggers. Environmental Impact and Potential Hazards. Nova Science Publishers, New York, pp 305-326

Piaget J, Inhelder B (1969) The psychology of the child. Basic Books, New York

Preston J (2012) Disaster education 'race,' equity and pedagogy. Sense Publishers, Rotterdam

Quinn FM (2000) The principles and practice of nurse education. Nelson Thornes, Cheltenham

Reed M, Evely A, Cundill G et al (2010) What is social learning? EcolSoc. https://doi.org/10.5751/ ES-03564-1504r01

Rodela R (2013) The social learning discourse: trends, themes and interdisciplinary influences in current research. Environ Sci Policy 25:157-166. https://doi.org/10.1016/j.envsci.2012.09.002

Samaddar S, Akudugu J, Oteng-Ababio M et al (2019) Stakeholders' perceptions on effective community participation in climate change adaptation: combating climate change by adaptation. Sustainable solutions for food security: combating climate change by adaptation. Springer International Publishing, New York, pp 355-379

Samaddar S, Choi J, Misra BA, Tatano H (2015) Insights on social learning and collaborative action plan development for disaster risk reduction: practicing yonmenkaigi system method (YSM) in flood-prone Mumbai. Nat Hazards 75:1531-1554. https://doi.org/10.1007/s11069-014-1380-4

Samaddar S, Okada N, Jiang X, Tatano H (2018) Who are pioneers of disaster preparedness? -insights from rainwater harvesting dissemination in Bangladesh. Environ Manage 62:474-488. https://doi. org/10.1007/s00267-018-1071-0

Santrock JW (2018) Educational psychology, 6th edn. McGraw-Hill Education, New York

Schultz D (2013) A History of modern psychology. Academic Press, Amsterdam

Schunk DH (2012) Learning theories: an educational perspective, 6th edn. Pearson, Boston 
Scrimsher S, Tudge J (2003) The teaching/learning relationship in the first years of school: some revolutionary implications of Vygotsky's theory. Early Educ Dev 14:293-312. https://doi.org/10.1207/s1556 6935eed1403_3

Seebauer S, Ortner S, Babcicky P, Thaler T (2019) Bottom-up citizen initiatives as emergent actors in flood risk management: mapping roles, relations and limitations. J Flood Risk Manag 12:e12468. https:// doi.org/10.1111/jfr3.12468

Shaw R, Shiwaku K, Takeuchi Y (2011) Disaster education. Bingley, Emerald

Shiroshita H, Yamori K (2011) Participatory disaster management learning built on the theory of legitimate peripheral participation. J Disaster Res 6:258-270

Shiwaku K, Sakurai A, Shaw R (eds) (2016) Disaster resilience of education systems: experiences from Japan. Springer, Tokyo

Siemens G (2005) Connectivism: a learning theory for the digital age. Int J Instr Technol Distance Learn. http://www.itdl.org/Journal/Jan_05/article01.htm. Accessed 7 May 2020

Southern California Earthquake Center (2020a) How To Protect Yourself During An Earthquake. In: Earthquake Country Alliance. https://www.earthquakecountry.org/dropcoverholdon/. Accessed 13 Apr 2020

Southern California Earthquake Center (2020b) Step 5: Drop, Cover, and Hold On. In: Earthquake Country Alliance. https://www.earthquakecountry.org/step5/. Accessed 13 Apr 2020

Sternberg RJ, Williams WM (2010) Educational psychology, 2nd edn. Merrill, Upper Saddle River, NJ

Takano N, Atsumi T (2007) An examination of the dialogue with the narrators and audiences of the Great Hanshin-Awaji earthquake: from several cases of the rips of the narrators' talks and audiences. Jpn J ExpSocPsychol 46:185-197. https://doi.org/10.2130/jjesp.46.185

Tanwattana P (2018) Systematizing community-based disaster risk management (CBDRM): case of urban flood-prone community in Thailand upstream area. Int J Disaster Risk Reduct 28:798-812. https:// doi.org/10.1016/j.ijdrr.2018.02.010

Thomas A, Menon A, Boruff J et al (2014) Applications of social constructivist learning theories in knowledge translation for healthcare professionals: a scoping review. Implement Sci 9:54. https://doi. org/10.1186/1748-5908-9-54

UNESCO (2020a) UNESCO Global Geoparks. In: Earth Sciences. http://www.unesco.org/new/en/naturalsciences/environment/earth-sciences/unesco-global-geoparks/. Accessed 15 Apr 2020

UNESCO (2020b) Fundamental Features. In: UNESCO Global Geoparks. http://www.unesco.org/new/ en/natural-sciences/environment/earth-sciences/unesco-global-geoparks/fundamental-features/. Accessed 15 Apr 2020

UNISDR (2015) Sendai Framework for Disaster Risk Reduction 2015-2030

Vygotsky LS (1978) Mind in society: the development of higher psychological processes. Harvard University Press, Cambridge

Weibell CJ (2011) Principles of learning: a conceptual framework for domain-specific theories of learning Ph.D. Brigham Young University

Wenger E (2009) Communities of practice: a brief introduction. In: Communities of practice. http://www. ewenger.com/theory. Accessed 16 Apr 2020.

Wood D, Bruner JS, Ross G (1976) The role of tutoring in problem solving. J Child Psychol Psychiatry 17:89-100. https://doi.org/10.1111/j.1469-7610.1976.tb00381.x

Yamori K (2020) Disaster risk communication: a challenge from a social psychological perspective. Springer, Singapore

Yamori K (2011) Promoting 'everyday-life preparedness.' Nakanishiya, Kyoto, Japan

Yamori K (2012) Revisiting the concept of 'tsunami tendenko. J Jpn Nat Disaster Sci 31:35-46

Yamori K, Miyamoto T (eds) (2016) Science of disaster reduction developed in the field: five frontiers of community of practice. Shinyosha, Tokyo, Japan

Yardley S, Teunissen PW, Dornan T (2012) Experiential learning: transforming theory into practice. Med Teach 34:161-164. https://doi.org/10.3109/0142159X.2012.643264

Zimmerman BJ, Schunk DH (2003) Albert bandura: the scholar and his contributions to educational psychology. Educational psychology: a century of contributions. Lawrence Erlbaum Associates Publishers, Mahwah, NJ, US, pp 431-457

Publisher's Note Springer Nature remains neutral with regard to jurisdictional claims in published maps and institutional affiliations. 